\title{
Results of EAHP's 2018 Survey on Medicines Shortages
}

\author{
Nenad Miljković, ${ }^{1}$ Nicholas Gibbons, ${ }^{2}$ Aida Batista, ${ }^{3}$ Raymond William Fitzpatrick, \\ Jonathan Underhill, ${ }^{2}$ Petr Horák ${ }^{4}$
}

${ }^{1}$ Hospital Pharmacy, Institute of Orthopaedic Surgery Banjica, Belgrade, Serbia

${ }^{2}$ School of Pharmacy, Keele University, Centre for Medicines Optimisation, Keele, UK

${ }^{3}$ Pharmacy, Centro Hospitalar Vila Nova de Gaia/Espinho, EPE, Vila Nova de Gaia, Portugal

${ }^{4}$ Hospital Pharmacy, University Hospital Motol, Prague 5, Czech Republic

\section{Correspondence to} Nenad Miljković, Hospital Pharmacy, Institute of Orthopaedic Surgery Banjica, Belgrade 11000, Serbia; nenad.miljkovic@iohbb.edu.rs

Received 11 December 2018 Revised 10 January 2019 Accepted 11 January 2019 Published Online First 4 February 2019

EAHP Statement 2: Selection, Procurement and Distribution. EAHP Statement 3 : Production and Compounding. EAHP Statement 4: Clinical Pharmacy Services. EAHP Statement 5: Patient Safety and Quality Assurance.

\section{ABSTRACT}

Aims and objectives The aim of the 2018 EAHP

Survey on Medicines Shortages was to provide a clearer picture on the issue of medicines shortages, including the impact on hospital pharmacists' time, budgets and the effect on patient care.

Methods A survey was conducted by the EAHP, collecting information from European hospital pharmacists on the shortage situation in their respective countries. The survey ran from 19 March 2018 to 11 June 2018. Keele University, UK analysed and compared the results to those of the 2014 survey.

Results There were 1666 responses to the 2018 survey, which represented a threefold increase from the 2014 survey which received 607 responses. Ninety per cent of respondents answered 'Yes' when asked if shortages of medicines are a current problem in delivering the best care to patients, while only $7 \%$ of respondents answered 'No', and 3\% 'Unsure'.

Problems with shortages of antimicrobials were most commonly reported (77\% of respondents reporting this as an issue in 2018 vs $57 \%$ in 2014), followed by preventative medicines (43\% in 2018 vs $20 \%$ in 2014) and anaesthetics (39\% in 2018 vs $27 \%$ in 2014). Fiftynine per cent of respondents have seen care delayed as a consequence of medication shortages, with cancellations of care (31\% of respondents), medication errors ( $25 \%$ of respondents) and suboptimal treatment for patients ( $25 \%$ of respondents) also being frequently reported. Sixty-three per cent of respondents reported having had to pay a higher price to procure from alternate sources most of the time or always when there was a shortage of a medicine.

Conclusions Medicines shortages is an increasing problem across Europe and is having an adverse impact on patient care. Medicines shortages are adding to hospital pharmacists' time pressures and have an adverse budgetary impact. More timely information about impending shortages and how long they will last is seen as necessary to help manage the problem.

\section{INTRODUCTION}

Representing one-sixth of all healthcare spending, medicines account for the third highest healthcare expenditure overall, not including those drugs used in hospitals which the OECD estimates would add an additional $30 \% .^{1}$ For $2017, £ 17.3$ bn was spent on medicines in the UK of which $£ 8$. 3 bn was for hospitals - $47.6 \%$ of medicine expenditures as compared with $32.1 \%$ in $2010 / 11$. $^{2}$ As hospitalised patients may require more complex treatment than in primary care and nearly every patient will receive some medicines, ${ }^{3}$ it is probable that medicine shortages will adversely affect patient care.

The EAHP's 2014 medicines shortages survey was conducted to assess the situation across Europe with medicine shortages and how they were affecting patient care as well as suggesting available solutions. ${ }^{4}$ When asked in 2014 if medicine shortages were a problem in their hospital, $86 \%$ of the 537 respondents responded 'yes'.

The EAHP statements of the hospital pharmacy 2017 survey identified barriers to the implementation of the EAHP Statements, one of which relates to medicines shortages $\left(2.5^{\prime}\right.$ Each hospital pharmacy should have contingency plans for shortages of medicines that it procures.'). Sixty per cent stated that they had reason to contact their respective medicines authority due to a shortage. The number of fully qualified hospital pharmacists was also a significant factor in determining whether a hospital has contingency plans to deal with medication shortages. ${ }^{5}$

The aim of the 2018 EAHP Survey on Medicines Shortages was to illuminate the impact of medicine shortages on hospital pharmacists and patient care, ${ }^{6}$ including:

- The current nature and prevalence of medicine shortages in Europe.

- The most common types of shortages.

- Their impact on patient care and hospital pharmacy services.

- Existing national mechanisms for dealing with or monitoring shortages.

- How hospital pharmacists typically manage the problems shortages cause.

- Hospital pharmacist views on proposed policy solutions.

\section{METHODS}

The EAHP created the 2018 Survey on Medicines Shortages using SurveyMonkey which they distributed to hospital pharmacists throughout Europe (http://www.eahp.eu/sites/default/files/report_medicines_shortages2018.pdf). The survey was shared together with its objectives, timeline with member associations and requested input. A consistent advertising campaign on social media (Facebook, LinkedIn and Twitter) and via the EU Monitor was used to engage individual hospital pharmacists. There were 32 questions, asking pharmacists of their experiences of shortages, their effect on patients, time consumed and budgets. The survey ran from 19 March 2018 to 11 June 2018. Keele University was commissioned to analyse and compare the results compared with those of the 2014 survey. 


\begin{tabular}{lcclcc} 
Table 1 & Response rates by participating countries & \\
\hline Country & $\begin{array}{l}\text { Responses } \\
(\mathbf{2 0 1 8})\end{array}$ & $\begin{array}{l}\text { Responses } \\
(\mathbf{2 0 1 4 )}\end{array}$ & Country & $\begin{array}{l}\text { Responses } \\
(\mathbf{2 0 1 8})\end{array}$ & $\begin{array}{l}\text { Responses } \\
(\mathbf{2 0 1 4})\end{array}$ \\
\hline Albania & 1 & 0 & Latvia & 4 & 2 \\
Austria & 29 & 21 & Lithuania & 1 & 8 \\
\hline Belgium & 90 & 94 & Luxembourg & 3 & 0 \\
\hline Bosnia \& & 19 & 9 & Malta & 6 & 11 \\
Herzegovina & & & & & \\
\hline Bulgaria & 3 & 6 & Montenegro & 4 & 0 \\
\hline Croatia & 26 & 25 & Netherlands & 20 & 11 \\
\hline Cyprus & 2 & 1 & Norway & 21 & 11 \\
\hline Czech Republic & 26 & 4 & Poland & 32 & 13 \\
\hline Denmark & 10 & 25 & Portugal & 85 & 42 \\
\hline Estonia & 17 & 15 & Romania & 24 & 2 \\
\hline Finland & 33 & 1 & Russia & 1 & 0 \\
\hline France & 192 & 3 & Serbia & 20 & 8 \\
\hline FYROM & 14 & 4 & Slovakia & 23 & 16 \\
\hline Germany & 78 & 10 & Slovenia & 18 & 5 \\
\hline Greece & 84 & 14 & Spain & 190 & 105 \\
\hline Hungary & 33 & 12 & Sweden & 5 & 0 \\
\hline Iceland & 9 & 4 & Switzerland & 67 & 7 \\
\hline Ireland & 51 & 47 & Turkey & 61 & 5 \\
\hline Italy & 73 & 41 & UK & 291 & 7 \\
\hline & & & & & \\
\hline
\end{tabular}

\section{RESULTS}

One-thousand six-hundred and sixty-six responses were given to the 2018 survey (threefold against the 607 responses of 2014). The table 1 below breaks down the responses of both survey years by country.

\section{Medicine shortages and their extent}

Ninety per cent of respondents answered 'Yes' when asked if shortages of medicines are a current problem in delivering the best care to patients. Only 7\% of respondents answered 'No', while $3 \%$ were 'Unsure'. Figure 1 breaks down the frequency of medicine shortages by country. Based on 1666 responses, the most frequent response was 'weekly' at 39\%, followed by 'daily' (36\%), 'monthly' (16\%) and 'occasionally' (11\%).

The results indicate a growing problem since 2014. The percentage of respondents by country reporting shortages to be a problem in terms of delivering the best care to patients and/ or operating the hospital pharmacy saw a statistically significant increase for 2018 (mean=91.8\%) compared with 2014 (mean $=82.6 \% ; \mathrm{P}=0.011$ ). A paired samples t-test also demonstrated a statistically significant increase in the mean percentage by country of respondents reporting more than 5 hours per week spent handling medicine shortages for the 2018 survey (mean $=42.0 \%)(2014:$ mean $=33.1 \% ; \mathrm{P}=0.031)$.

Figure 2 details which medicine group most frequently experiences shortages in hospitals. As with 2014, antimicrobial agents in 2018 were most frequently reported (77\% of the 1348 respondents). Antimicrobial agents received the most reports for 27 countries, although this was not always the case: six countries reported anaesthetic agents, as well as singular reports for oncology, haematology, emergency and cardiovascular medicines. Although preventative medicines (eg, vaccines) were the second highest reported area (43\% of participants), they were not the most frequently reported medicine shortage in any single country.

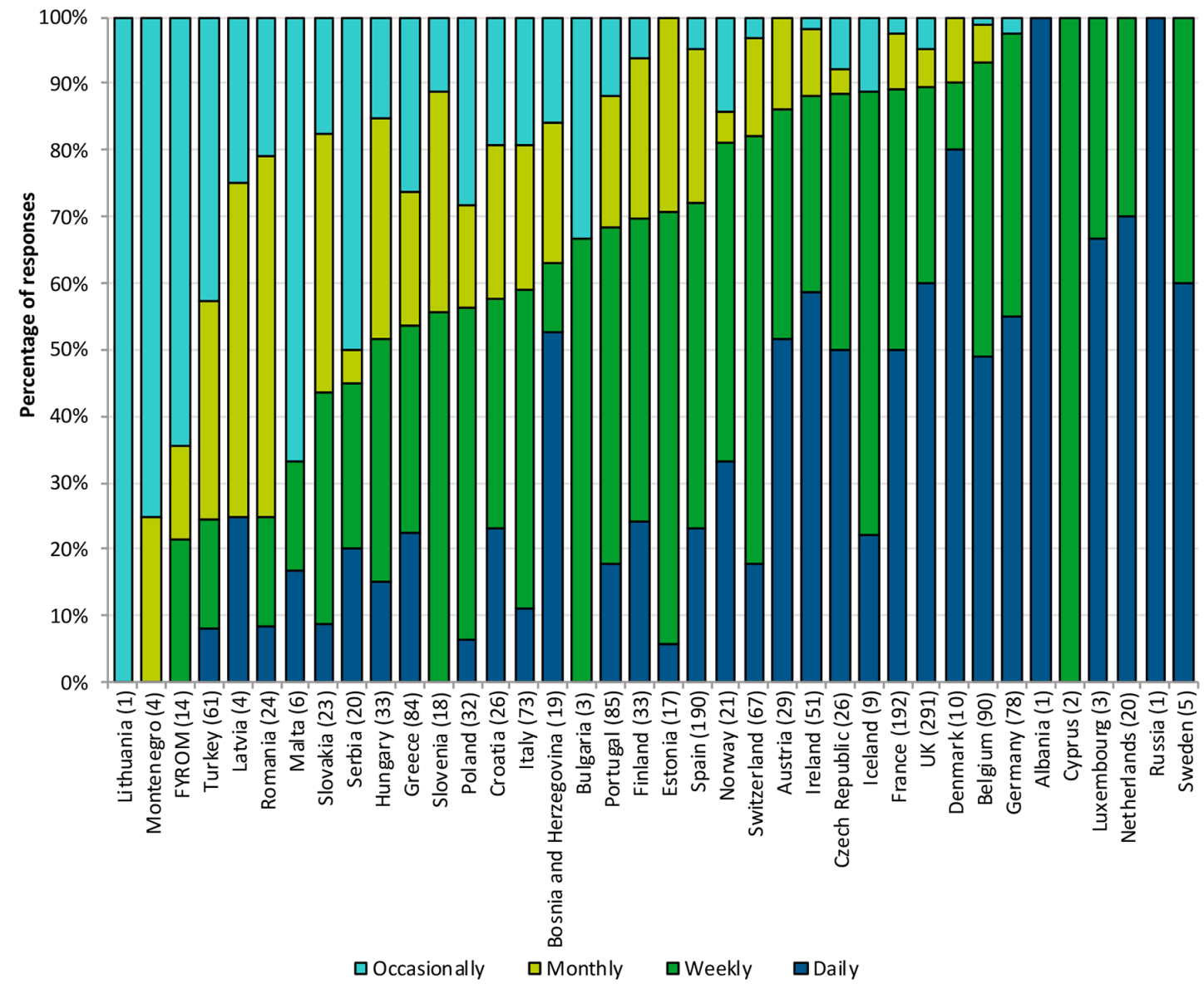

Figure 1 Percentage of responses for the question 'Approximately how often does your hospital pharmacy experience medicines shortages?', grouped by country. Numbers in brackets represent number of responses from that country. 


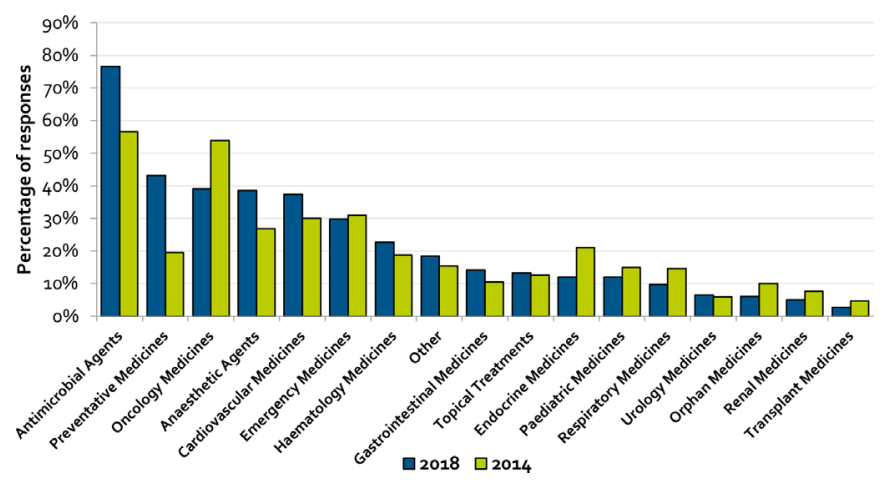

Figure 2 Percentage of participants in the survey who identified this area of medicine to be commonly in short supply. $(n=1,348)$ (Note that this was a tick all that apply question.)

Among responses from the 'other' category were drugs related to mental health or antipsychotics (87 responses), followed by contrast/X-ray medicines (25 responses), analgesics (24 responses) and immunoglobulins (24 responses).

As with 2014, the most common reported shortages again were antimicrobial agents $(77 \%, 2018 ; 57 \%, 2014)$, preventative medicines $(43 \%, 2018 ; 20 \%, 2014)$ and anaesthetic medicines $(39 \%, 2018 ; 27 \%, 2014)$, suggesting shortages in these areas have become more frequent. The biggest decrease was in oncology medicine $(39 \%, 2018 ; 54 \%, 2014)$.

The medicine most frequently associated with supply issues was piperacillin/tazobactam with 272 responses across 18 countries. Other commonly mentioned antimicrobials were cephalosporins (86 responses, 20 countries), gentamicin (80 responses, seven countries) and co-amoxiclav (67 responses, 10 countries).

A number of respondents reported experiencing shortages in all vaccinations without specification (144 responses, 18 countries). However, those most frequently specified were hepatitis B (65 responses), pneumococcal (27 responses), tuberculosis (25 responses), tetanus (17 responses) and hepatitis A (17 responses).

There were 99 generally non-specific responses across 13 countries for immunoglobulins. With 28 responses, Privigen was the most frequent.

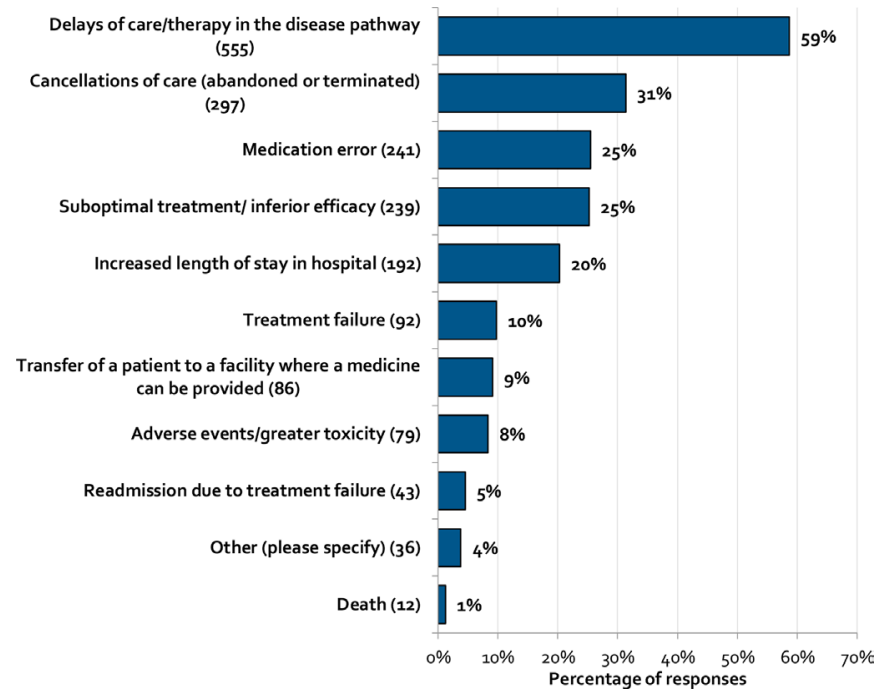

Figure 3 Percentage of participants in the survey who identified this category of impact on patient care due to medicines shortage. $(n=946)$ (Note that this was a tick all that apply question.).

\section{Reported experiences of hospital pharmacists}

When a medicine is in short supply, a hospital pharmacist will try to ensure against adverse effects in treatment. The hospital may have sufficient supplies to last through the shortages: informed in advance, they may try to stockpile the medicine. If a medicine is not available, pharmacy teams may look to find an alternate supplier or source of the medicine, possibly from abroad. This may include using different brands of the same medicine. In some cases where this is not possible, either the pharmacist or the prescriber may recommend a complementary medicine to be used instead.

Respondents were asked to provide details about their own personal experiences with typical shortage situations and how they are managed. One theme that emerged was the lack of reliable or timely information from manufacturers and suppliers on the commencement or duration of shortages.

- "Mostly there is no Information provided from the manufacturer. It should be as soon as possible, in detail and continuously"-Austria.

- "The worst is, that pharmaceutical companies do not communicate; the orders are not delivered, and the information mostly is only achieved by asking the supplier." - Germany.

- "We are not informed about shortage, information from manufacturers is missing” - Czech Republic.

Apparently, the more advanced the notice is, the better hospital pharmacists are able to manage a shortage. Sometimes a shortage is only discovered when the products are not delivered.

- "When there is sufficient or any notice they are easier to manage. Dealing with shortages when we get notice that the product is out of stock is much more challenging and reactive." - Ireland.

- "Not good.I found about shortage when wholesaler cannot deliver drugs when I order them" - Croatia.

- "Lack of information on availability from manufacturer and their wholesalers, lack of pre-warning of shortage resulting in panic buying, excess stock holding by some trusts, lots of time spent chasing orders, getting conflicting information, lots of time wasting trying to sort out what can be used as a replacement." - UK.

Many respondents commented that suppliers do not reliably inform them when the stock will return. It has even become normalised to assume the date will be pushed back several times.

- "Very often the companies announce a duration of the shortage which isn't correct, so it goes longer and longer all the time. It would be better in this case to describe the duration as unknown" - Switzerland.

- "In most cases there is no data when the product will be delivered again (end of shortage). When a firm does have a delivery-date, you cannot always depend on it!" - Belgium.

- "... Then there will be information on when the drug is expected to be delivered again - but this information is never to be trusted. That is in my opinion the biggest problem because we never know how to advice the hospital."-Norway.

\section{Effect on patients}

Figure 3 displays the impact medicine shortages have had on patient care in the past year. Over half of the 946 respondents saw care delayed as a consequence of medication shortages (59\%), while the quality of care received is directly affected by care cancellations (31\%). Medication errors (25\% of respondents) and suboptimal treatment $(25 \%)$ are also frequently reported. When asked to provide specific examples of the effect shortages have on patient care, these included 'Cancellation of cure (sic) 
for shortage of polyvalent immunoglobulins' (denoting that the treatment had to be ended) - France and "Delay in care or being prescribed second line antibiotics for an infection. Being forced to prescribe broader spectrum antibiotics because narrower spectrum was not available and increase risk for antimicrobial resistance" - Ireland. There were 12 reports of death being caused as a consequence of medication shortages ( $1 \%$ of respondents).

Reported events such as increased length of hospital stay $(20 \%$ of respondents) and readmissions due to treatment failure (5\%) put further strain on capacity and budgetary pressuers: "Longer wake up times after OP, because of Remifentanyl shortage-Impact on Duration of the stay in intensive care unit - less beds to offer - less surgery possible" - Switzerland and "Psychiatric patients stopped their therapy and it caused readmissions."-Croatia.

Although not listed as a specific option, 19\% of respondents chose none of the responses. The 'Other' category was also varied, with five claiming no impact on patient care, and four reiterating burden of dealing with shortages and having less time to focus on patient care.

Some respondents were unsure of any impact because they do not interact with patients (eg, "No access to this data as hospital pharmacists in Croatia are not included in clinical circle and have no access to hospital wards, no insight in patient files or contact with patients at all."- Croatia).

\section{Effect on pharmacists' time and budgets}

Managing medication shortages can be extremely time-consuming, as additional work is needed for procurement and informing other hospital staff of the situation. Some hospitals have taken measures to mitigate shortages, such as hiring staff dedicated to the issue or determining durations as based on previous data:

- "We document every delivery shortage and can therefore determine the typical duration."-Germany.

- “... I have to create a 'shortage memo' for all relevant medical, nursing \& pharmacy staff to inform them of the latest shortage (every time), proposed alternative, expected timeframe for shortage \&o any other important information (if alternative product is majorly different to original/needs manipulation etc)." - Ireland.

- "We have a full time post who spends all her time managing supply shortages and we are looking at needing to add additional resources to support this due to the growing issues"-UK.

Figure 4 presents the estimated time spent handling shortages according to country, sorted by the percentage of respondents reporting at least 5 hours per week.

The most frequent response to the question asking how much time was spent per week was 'up to 5 hours' (46\% of 969 respondents). More respondents selected the highest duration option ('more than 15 hours', 13\%) than the lowest duration option ('less than 1 hour', 11\%).

The mean percentage of a country's respondents report more than 5 hours per week managing medicine shortages for the 2018 survey $($ mean $=42.0 \%)$, compared with 2014 (mean=33.1\%). A paired samples t-test shows a statistically significant $(\mathrm{P}=0.031)$ increase compared with the 2014 survey.

Budgetary issues caused by medication shortages can be attributed to their required procurement from another supplier or higher costs of alternatives. Needing to devote more staff time

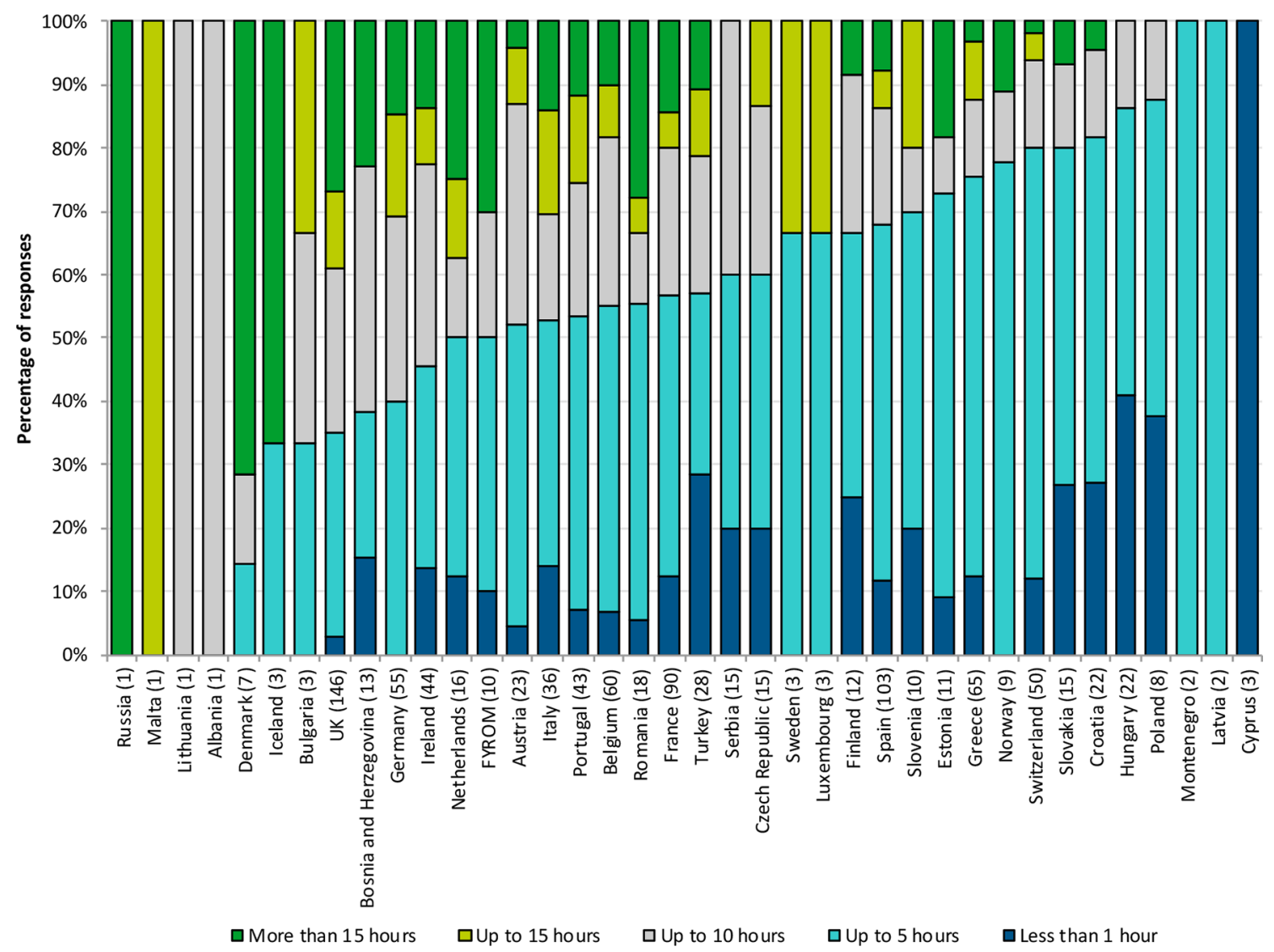

Figure 4 Percentage of responses for the question 'In an average week in your hospital, how much time (staff working time) do you estimate is diverted because of medicines shortage problems?', grouped by country. $(n=969)$. Numbers in brackets represent number of responses from that country. 


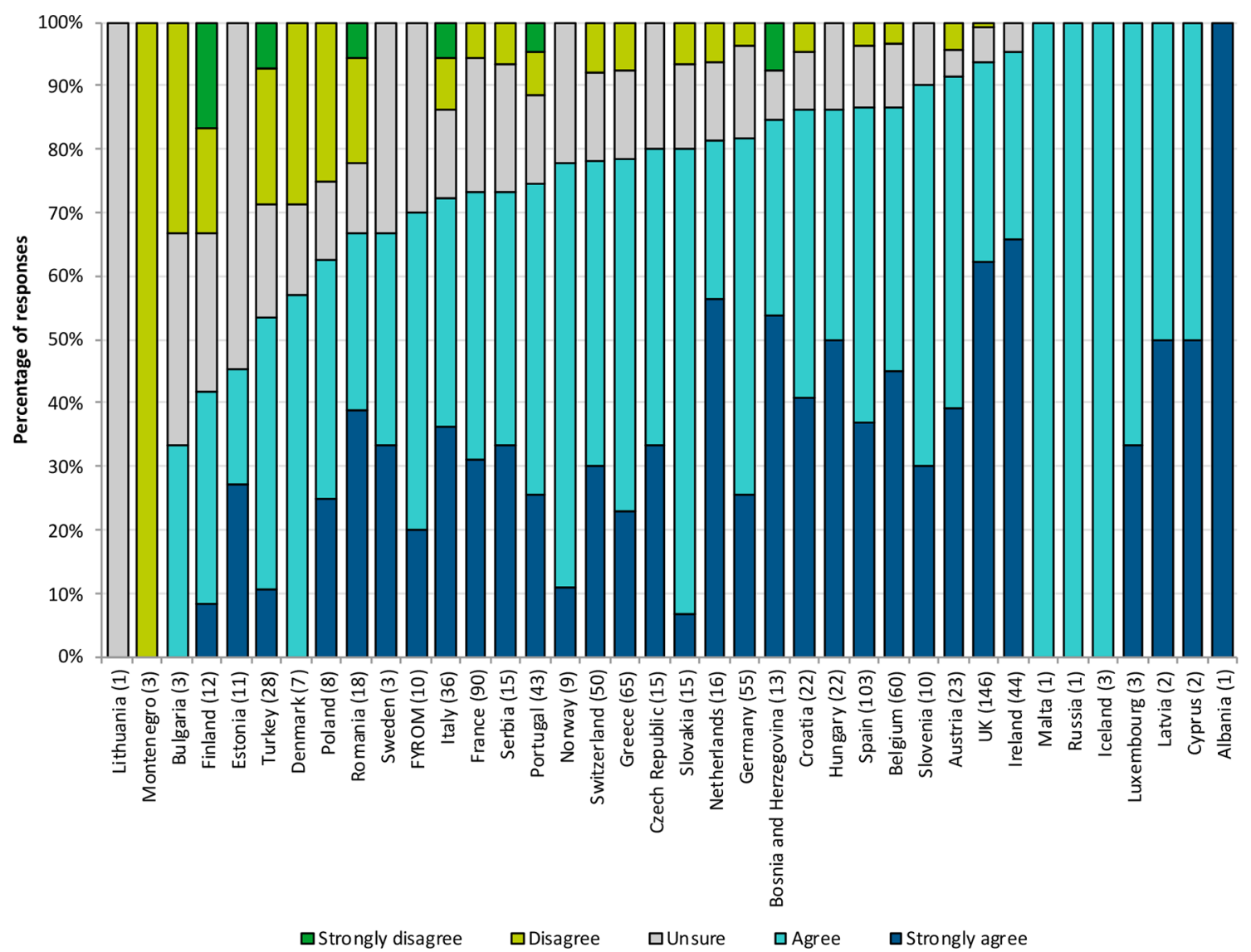

Figure 5 Percentage of responses for the question 'Do you agree with the following statement?"' Medicines shortages in my hospital are having a negative impact on my overall budget."', grouped by country. (n=969). Numbers in brackets represent number of responses from that country.

to the issue as well as the impact on the patient also contributes to budgetary pressures. When asked if medicine shortages are having a negative impact on overall budget, most chose either 'agree' (43\% of responses) or 'strongly agree' (38\%) (figure 5).

When asked how often they have to pay a higher price to procure a drug from another supplier/hospital, 63\% $(n=969)$ reported regularly having to pay a higher price from alternate sources (46\% most of the time, $17 \%$ all of the time). Only $6 \%$ reported rarely paying a higher price with $2 \%$ reporting never having to.

\section{Solutions suggested by respondents}

When asked how often they estimate their hospital is able to provide treatment to patients by providing a therapeutic equivalent or near equivalent medicine without major disruption to their treatment, $78 \%$ responded 'most of the time' or 'all of the time'. While hospital pharmacists spend considerable time and resources ensuring that patient care is not adversely affected, it is not considered sustainable ("We have so far always managed to source a timely alternative - but unsure how long this will be sustained"-UK).

Freetext recommendations to the proposed solutions to manage the shortage issues include mandatory reporting of shortages by manufacturers and providing accurate information on return dates (10 responses). Eight responses called on manufacturers to have a legal obligation to maintain stock levels and ensure supply of medicines. An equal number called for a central lead/agency to work on the issue in order to avoid unnecessary duplication of efforts in identifying alternatives (at European, EU or national level).
Identifying the root cause of shortages is also seen as important - "A more holistic review needs to be undertaken to understand why shortages occur and try and prevent them. Currently most shortages are managed reactively instead of proactively."-UK.

\section{DISCUSSION}

The 2018 survey clearly indicates that medicine shortages are getting worse. There was a threefold increase in respondents reporting problems compared with 2014 and a statistically significant increase in the proportion of respondents stating medicine shortages were adversely affecting their ability to provide the best care for their patients. It is quite alarming that $75 \%$ of respondents experienced medicines shortages on a weekly or daily basis (figure 1). It is also of concern that antimicrobials were the most commonly cited medicine for both 2014 and 2018 as there are few new antimicrobials entering the market, while resistance to existing agents is an increasing concern. ${ }^{7}$

Conversely, there was a decrease in respondents citing shortages in oncology medicines compared with 2014 , although $40 \%$ of respondents were still experiencing problems in this area. A possible explanation could be that more biosimilar medicines have been approved for cancer treatment since $2014^{8}$ which has increased competition in the biologics market, possibly leading to an impact on shortages in this area.

Although hospital pharmacists are doing their best to find alternative sources or medicines to minimise the impact on clinical care, medicine shortages still cause delays in care and cancellation of treatment, as well as contribute to medication errors. Not all respondents assessed the impact of medicine shortages on patient care due to varying hospital pharmacist roles between 
countries (the EAHP Statement Survey notes it to be entirely focused on procurement in some countries while there is a clinical focus and more patient contact in others ${ }^{9}$ ).

Hospitals in most healthcare systems are experiencing capacity and budgetary pressures stemming from the ageing population and complexity of diseases being treated. The 2018 survey underscores that medicines shortages add to these pressures given the statistically significant increase in the number of respondents reporting spending more than 5 hours per week as compared with 2014 (lost capacity that could otherwise be used for improving patient outcomes). EAHP surveys suggest insufficient capacity to be a crucial barrier to implementing European Statements of Hospital Pharmacy. ${ }^{3}$ Respondents also highlighted the need to pay more for medicines during a shortage.

Lack of timely information about medicines shortages appears to hinder hospital pharmacists' effective management of medicine shortages. Many respondents would therefore like

\section{What this paper adds}

\section{What is already known about the subject}

- Medicines shortages were reported in several European countries in the 2014 survey.

- Cases of patient harm have been reported as a direct result of medicines shortages.

\section{What does this study add}

- Medicines shortages appear to be increasing across Europe, with $75 \%$ of respondents reporting weekly or daily medicine shortages.

- An increased frequency of cases of direct harm to patients due to medicines shortages.

- Costs of obtaining medicines under shortages are elevated.

- Medicines most frequently in short supply were antimicrobials (a particular concern given the drive to improve antimicrobial stewardship in order to reduce antimicrobial resistance).

- Lack of timely information about medicines shortages is hampering hospital pharmacists' ability to manage medicines shortages effectively. manufacturers to have a legal obligation to maintain stock levels and ensure supply of medicines or a central lead/agency to work on the problem to reduce duplication of efforts in identifying alternatives (either at European, EU or national level).

\section{CONCLUSION}

The EAHP 2018 Medicines Shortages Survey indicates shortages have an adverse impact on patient care by adding to hospital pharmacists' time pressures and budgets. More timely information about impending shortages and how long they will last is seen as necessary to help manage the problem.

Contributors AB, NM, PH and Stephanie Kohl (EAHP Policy \& Advocacy Officer), as a collaborator, were responsible for survey conception and design, as well as acquisition of data via SurveyMonkey. NG, RWF, JU were responsible for the analysis, while $A B, N M, P H$ were involved in analysis and interpretation of data. All authors discussed the results and contributed to the final manuscript.

Funding This research is supported by an unrestricted educational grant from Amgen.

Competing interests None declared.

Patient consent for publication Not required.

Provenance and peer review Not commissioned; internally peer reviewed.

\section{REFERENCES}

1 OECD. Health at a Glance: Europe 2018 State of Health in the EU Cycle. Paris/EU, Brussels: OECD Publishing, 2018.

2 Prescribing and Medicines Team, NHS Digital. Prescribing Costs in Hospital and Community in England 2016/17: NHS Digital, 2017.

3 Commission for Healthcare Audit and Inspection. The best medicine - the management of medicines in acute and specialist trusts. London: Commission for Healthcare Audit and Inspection, 2007

4 EAHP. Medicines Shortages in European Hospitals - The evidence and case for action. 2014 http://www.eahp.eu/sites/default/files/shortages_report05online.pdf.

5 Underhill J, Batista A, Horák P, et al. EAHP European Statements Survey 2017, focusing on sections 2 (Selection, Procurement and Distribution), 5 (Patient Safety and Quality Assurance) and 6 (Education and Research). Eur J Hosp Pharm 2018;25:237-44.

6 EAHP. 2018 medicines shortage survey EAHP's 2018 survey on medicines shortages to improve patient outcomes. 2018 http://www.eahp.eu/practice-and-policy/medicinesshortages/2018-medicines-shortage-survey.

7 World Health Organisation. Antimicrobial Resistance Global report on Surveillance. Geneva: World Health Organisation, 2014.

8 Santos SB, Sousa Lobo JM, Silva AC. Biosimilar medicines used for cancer therapy in Europe: a review. Drug Discov Today 2018.

9 Horák P, Peppard J, Sýkora J, et al. EAHP European Statements baseline survey 2015: results. Eur J Hosp Pharm 2016;23:69-75. 